\title{
Extended phenotypes on coral reefs: cryptic phenotypes and species interactions
}

\author{
Anya Brown ${ }^{1}$, Elizabeth Hamman ${ }^{2}$, Jeffrey Shima ${ }^{3}$, John Wares $^{2}$, and Craig Osenberg² \\ ${ }^{1}$ University of Florida \\ ${ }^{2}$ University of Georgia \\ ${ }^{3}$ Victoria University of Wellington
}

May 5, 2020

\begin{abstract}
If phenotypic plasticity is adaptive, then prior exposure to a stressor should reduce effects arising from subsequent stressor exposure. Here, we test the hypothesis that corals exhibit adaptive plasticity to a stressor (vermetid gastropods) mediated by their extended phenotype (coral-associated bacteria). We used a reciprocal transplant experiment to evaluate corals that varied in their prior exposure to vermetid gastropods, a known biotic stressor. We measured a suite of traits associated with coral performance, many of which showed a plastic response to vermetid exposure: decreased calcification, increased microbial diversity, and shifted microbial composition. Most traits (e.g., tissue thickness) also showed a signature of previous exposure environment that persisted after exposure reversal. These phenotypic differences are likely genetic, as reefs with and without vermetids largely comprised of two mitotypes. We suggest cryptic coral variation contributes to different community trajectories, with thin-tissue types more prone to disturbance and subsequent colonization by other species.
\end{abstract}

\section{Hosted file}

ExtendedPhenotype_EcoLetteres_tosubmit3.docx available at https://authorea.com/users/302187/ articles/432494-extended-phenotypes-on-coral-reefs-cryptic-phenotypes-and-speciesinteractions 